\title{
Unidades de conservação como estratégia de gestão territorial dos recursos naturais
}

\section{Conservation units as a territorial management strategy for natural resources}

\author{
Maria do Socorro Ferreira da Silva \\ Rosemeri Melo e Souza \\ Universidade Federal do Sergipe
}

\begin{abstract}
Resumo: No Brasil, as Unidades de Conservação (UCs) são utilizadas enquanto mecanismos de gestão territorial para proteger os recursos naturais que restaram ao país após um intenso processo de depleção. Para compreender as relações existentes nas UCs fazse necessário um resgate teórico acerca da categoria de análise geográfica, o território, considerado como instrumento de exercício de poder. Nessas relações, observa-se o envolvimento de atores inseridos nos espaços territoriais legalmente protegidos, gerando o processo contínuo de territorialização-desterritorialização-reterritorialização. Aqui, prevalecem as relações de poder estabelecidas pelos grupos dominantes nem função das áreas detentoras de maior biodiversidade mundial como o Brasil.
\end{abstract}

Palavras-chave: Biodiversidade. Unidades de conservação. Gestão territorial.

\begin{abstract}
Conservation Units (CUs) are tools for territorial management in Brazil to protect natural resources that have been spared from the country's intense process of depletion in the past. To understand the functioning of these Conservation Units it is necessary to develop a theory that investigates analytically the geographical category of territory that is regarded as an instrument for the exercise of power. Here, the participation of actors can be observed in the continuous process of desterritorializationterritorialization-reterritorilization in spaces that are legally protected. In these spaces power relations are established by hegemonic groups that are controlling the areas of the greatest biodiversity in the world, as it is the case in Brazil.
\end{abstract}

Keywords: Biodiversity. Conservation units. Territorial management. 


\section{INTRODUÇÃO}

O Brasil encontra-se no alto da lista de países detentores de maior biodiversidade mundial. Conforme Copabianco et al. (2002) até 2002 , o país abrigava cerca $10,8 \%$ de espécies de plantas com semente, 17,2\% de mamíferos, $15 \%$ de anfíbios, e 10,7\% de peixes de todo o mundo. Dentre essas espécies cabe ressaltar que muitas delas são endêmicas, ou seja, são restritas a uma determinada área.

Notadamente, diante desse potencial de biodiversidade o país passa a chamar a atenção dos países do Norte que necessitam de matéria-prima para atender às necessidades da indústria da biotecnologia. Dessa forma, políticas de conservação dos recursos naturais, tanto na esfera internacional como nacional, são criadas em função dos territórios considerados como "megadiversos", os quais possuem juntos cerca de $70 \%$ da diversidade biológica mundial. Dessa forma, o país tem a responsabilidade de proteger várias de suas espécies, ecossistemas naturais e processos biológicos que tornam o planeta habitável.

Após o reconhecimento das falhas apresentadas na utilização dos produtos químicos da indústria da agricultura e de medicamentos, a biodiversidade passa a ser vista como fornecedora de matériaprima para suprir tais necessidades, assim como para a acumulação de capital continuada, e o controle sobre os mercados e os recursos naturais (SHIVA, 2005). Nessa análise, fica evidente tanto o interesse dos países desenvolvidos em reservar parcelas dos territórios detentores de biodiversidade para interesses futuros. Assim, não se pode descartar a hipótese dessas UCs estarem sendo criadas como mecanismo de alienação do território, para mais adiante serem utilizadas com outros interesses e não para as gerações futuras, como é propagado.

Com relação ao capital interno, há evidências de que essas áreas estão sendo reservadas para mais adiante atenderem as necessidades do agronegócio, neste caso, como estoque de terras para o avanço da atividade agrária.

Contudo, apesar da importância dos recursos biofísicos, os impactos ambientais, como o desmatamento, as queimadas, a contaminação dos solos, do ar e dos recursos hídricos, colocam em risco a conservação dos ecossistemas naturais. Mesmo após a criação de espaços territoriais protegidos, como as UCs, percebe-se a contínua depleção desses ambientes. Nessa ótica, pode-se dizer que o desenvolvimento humano da sociedade capitalista sem destruir a base biológica é sem dúvidas um grande desafio que será enfrentado no decorrer do século XXI.

No Brasil, os espaços territoriais demarcados, com a função de proteção dos recursos naturais e/ou culturais, as primeiras áreas protegidas foram criadas em 1861, as Florestas da Tijuca e das Paineiras. Em 1961 a Floresta da Tijuca recebeu a denominação de Parque Nacional do Rio de Janeiro pelo Decreto No 50.923, de 6/07/1961, e em 1967 teve o nome alterado para Parque Nacional da Tijuca pelo Decreto $N^{\mathrm{o}} 60.183$, de 8/02/1967 (BRASIL, 2004). Apesar dessa preocupação com a proteção dos recursos naturais a primeira UC foi instituída legalmente apenas em 1937, sob forma de Parque Nacional.

Num contexto histórico, as áreas de proteção do país passaram por momentos distintos, tendo como marco a criação do Código Florestal em 1934. Atualmente os espaços protegidos encontram-se inseridos nas UCs estabelecidas pelo Sistema Nacional de Unidades de Conservação - SNUC (Lei no 9985, de 18 de julho de 2000), que as dividem em dois grupos, as UCs de Proteção Integral que tem como objetivo 
a preservação da natureza, admitindo-se apenas o uso indireto dos recursos naturais, com exceção dos casos previstos na referida Lei; e as de Uso Sustentável com o objetivo básico de compatibilizar a conservação da natureza com o uso sustentável de parcela dos recursos naturais existentes nesses espaços.

No primeiro grupo, encontram-se cinco categorias: Estação Ecológica, Reserva Biológica, Parque Nacional, Monumento Natural e Refúgio de Vidas Silvestres; e o segundo é composto por sete categorias: Área de Proteção Ambiental (APA), Área de Relevante Interesse Ecológica, Floresta Nacional (FLONA), Reserva Extrativista, Reserva de Fauna, Reserva de Desenvolvimento Sustentável e Reserva Particular do Patrimônio Natural (RPPN).

Entre os fatores que justificam e motivam a criação e implementação de UCs estão a perda da biodiversidade biológica; a vulnerabilidade para extinção de espécies; a degradação e fragmentação de hábitats; argumentos éticos relacionados à manutenção das espécies; e o valor econômico direto ou indiretamente relacionado à manutenção da biodiversidade. No entanto, esses espaços territoriais são permeados de conflitos de ordem política, legal e sócioeconômica-ambiental que vem dificultado à administração desses territórios.

Nesse sentido, o presente trabalho faz uma abordagem crítica e discursiva sobre as Unidades de Conservação consideradas como principal estratégia territorial para a proteção dos recursos naturais.

\section{O PAPEL DA ANÁLISE \\ DO TERRITÓRIO PARA A CONSERVAÇÃO DOS RECURSOS NATURAIS}

Para compreender os sentidos e implicações das categorias do Sistema Nacional de Unidades de Conservação (SNUC) há uma necessidade de resgatar o conceito de território à luz da categoria de Milton Santos, que considera território como uma extensão apropriada e usada. Num sentido mais restrito o território é um nome político para o espaço de um país. Já o sentido de territorialidade é o de "de pertencer aquilo que nos pertence", nesse sentido o território usado como sinônimo de espaço geográfico (SANTOS; SILVEIRA, 2001).

Ainda na análise de Santos e Silveira (2001), o território enquanto questão central na história da humanidade constitui-se como um pano de fundo na perspectiva de interpretação das diversas etapas e do momento atual de cada país. Sendo assim, para compreender os modos de regulamentação faz-se necessário analisar a forma de distribuição do trabalho em cada momento histórico, o que nos remonta a questão da compreensão da divisão territorial do trabalho que envolve a repartição do trabalho vivo dos lugares e a distribuição do trabalho morto e dos recursos naturais que consequentemente norteia a repartição do trabalho vivo.

Nesse sentido, a divisão territorial do trabalho dita as regras via hierarquia entre os lugares, redefinindo constantemente a capacidade agir das instituições, firmas e pessoas. Em outras palavras, o uso do território, a territorialidade, é definido pela implantação de infra-estrutura, pelo dinamismo da economia e da sociedade. Dessa forma, Santos e Silveira (1987; 1997 apud SANTOS; SILVEIRA, 2001) complementam que a configuração do espaço geográfico se dá através do movimento da população, da distribuição da agricultura, da indústria e dos serviços e do arcabouço normativo.

Na análise de Vallejo (2009), o conceito de território possui diferentes abordagens que dependem da ciência que o está utilizando. Nas Ciências Políticas, por exem- 
plo, o território está intimamente ligado à formação do Estado; na Antropologia, é muito utilizado em relação às sociedades tradicionais, em que os vínculos espaciais são bastante pronunciados. Já na Geografia, caracterizada como a ciência de integração entre o espaço físico e os processos sociais, o território não poderia deixar de ser uma categoria geográfica das mais importantes a serem analisadas (VALLEJO, 2009). O espaço é anterior ao território, pois o ator territorializa o espaço. Dessa forma, para Naranjo (2000 apud VALLEJO, 2009), "o território é um espaço geográfico ocupado por um ser ou conjunto de seres, sobre o qual se manifestam as relações de sobrevivência e reprodução".

A discussão do conceito de território no estudo das UCs apresenta várias possibilidades de análise, tanto no aspecto do "mundo natural" quanto nas questões relacionadas à sociedade, seja ela geral, ou comunidades sociais. $\mathrm{Na}$ análise do estudo das comunidades tradicionais a noção de território é influenciada pela experiência de vida, uma vez que a principal fonte de recursos é oriunda da natureza. As experiências das comunidades tradicionais são precursoras das práticas atuais de conservação de recursos naturais através de unidades de conservação, evidenciando uma prática territorial (VALLEJO, 2009). Trata-se, portanto, do que Santos e Silveira (2001) chamam de território usado, sinônimo de espaço geográfico. Dessa forma, a categoria de análise não é o território em si, mas o território usado.

$\mathrm{Na}$ abordagem "funcional-estratégica" de território como espaço em que se exerce domínio político, consequentemente controlo do acesso (HAESBAERT, 2003). Dessa forma, o conceito de território se aplica às Áreas Protegidas, mais especificamente as UCs, uma vez que o recorte espacial, que define uma fronteira, media uma relação de poder que efetivamente torna essa área um meio de influenciar e controlar pessoas, coisas e relações sociais. Trata-se do exercício de territorialidade, onde pessoas e recursos são controlados em função de uma área.

Godelier (1984 apud DIEGUES; NOGARA, 1999) traz algumas reflexões acerca do território, principalmente quando analisa os tipos de culturas e comunidades tradicionais. A noção de território é um elemento de grande relevância na relação entre populações tradicionais e a natureza. Nesse sentido, o autor define território como uma porção da natureza e espaço sobre o qual uma sociedade reivindica e garante a todos, ou a parte dos membros, direitos estáveis de acesso, controle e uso sobre os recursos naturais existentes. Sendo assim, esse recorte espacial, do mundo natural, fornece ao homem os meios de subsistência, de trabalho e de produção, de produzir os aspectos materiais das relações sociais. Conforme Diegues e Nogara (1999), o território dessas populações é diferente das sociedades urbanas, pois é descontínuo, marcado por vazios aparentes, o que sem dúvida os torna mais frágeis, no sentido mais restrito, no processo de desterritorialização dessas comunidades.

Haesbaert (2003) complementa a análise, enfatizando que a produção do espaço sempre envolve a desterritorialização e a re-territorialização, ou seja, na dinâmica do território sempre haverá a vida e a morte dos territórios, onde a vida social é vista como um movimento de territorializaçãodesterritorialização-reterritorialização. Nessa visão, as populações tradicionais são exemplos claros, pois estiveram por muito tempo enraizadas num determinado espaço territorial de onde retiravam seus sustentos, porém, após a transformação desse espaço em UC de Proteção Integral foram desterritorializadas passando a fazer parte de um aglomerado de exclusão. Nessa ótica, a tendência é de que os mais 
fracos sejam os principais atingidos.

A criação de espaços legalmente protegidos é vista como uma importante estratégia de controle do território, pois estabelece limites e dinâmicas de uso e ocupação. O controle e os critérios de uso aplicados nas UCs são atribuídos em função da valorização dos recursos naturais existentes nas localidades, ou pela necessidade de proteger biomas, ecossistemas e espécies raras ou ameaçadas de extinção (MEDEIROS, 2006).

Em termos legais, o SNUC define UCs como "espaço territorial e seus recursos ambientais, incluindo as águas jurisdicionais, com características naturais relevantes, legalmente instituído pelo Poder Público com objetivos de conservação e limites definidos, sob regime especial de administração, aos quais se aplicam garantias adequadas de proteção" (BRASIL, 2000).

Conforme Santos (1988), o mundo é organizado em subespaços articulados à lógica global. Santos e Silveira (2001, p. 255) acrescentam que "a lógica das grandes empresas, internacionais e nacionais, constitui um dado da produção política interna e da política internacional de cada país". Nesse contexto, a gestão do território caracteriza-se pelas relações de poder dos grupos sociais na busca pela satisfação de seus interesses num determinado espaço territorial, neste caso, dotado de biodiversidade.

Como exemplo desse controle descrito temos a Convenção sobre a Diversidade Biológica, um instrumento político internacional, que será analisado mais adiante, o qual influenciou na criação do Sistema Nacional de Unidades de Conservação no âmbito nacional. Assim, pode-se dizer que há um retalhamento dos espaços naturais, onde os territórios detentores de potencial de biodiversidade passam a ser controlados pelos grupos dominantes em função de interesses distintos.

As empresas globais necessitam de condições territoriais para sua produção e regulação. Diante do processo de globalização econômica, o espaço nacional é organizado para servir às grandes empresas e por isso pagam um preço, tornando-se fragmentado, incoerente, anárquico para todos os demais atores. Dessa forma, as empresas interessadas em determinados espaços territoriais, influenciam nações e lugares, entretanto, para funcionarem criam ordem para si mesmas e desordem para os outros países (SANTOS; SILVEIRA, 2001).

Nesse sentido, as empresas possuem interesses diversos que comumente geram conflitos entre grupos dominantes antagônicos em busca dos "territórios da conservação". Por um lado, os interessados em explorar o potencial biodiverso desses territórios para atender à indústria farmacológica, apoiando e incentivando a elaboração e manutenção de políticas de conservação para os ecossistemas naturais. E por outro lado, os que necessitam desses territórios para o avanço do agronegócio, advogando em favor da a redução das Áreas de Reserva Legal, por exemplo.

Diante do exposto, e da situação das UCs no Brasil, duas questões retornam ao tema central nesta análise: será que os verdadeiros interesses pelos territórios detentores de biodiversidade não estão sendo mascarados, e esses espaços estão sendo poupados para as necessidades da indústria farmacológica? Ou estão sendo utilizados como reserva/estoque para expansão do agronegócio, num mundo onde a discussão gira em torno da produção de energia e combustível a base de vegetais? Não seria por essa última questão que de fato não se tem tanto interesse na gestão efetiva desses espaços legalmente protegidos? 


\section{BIODIVERSIDADE E CONSERVAÇÃO DA NATUREZA}

Para Albagli (2001), a proteção da biodiversidade possui diferentes atores com motivações distintas. As corporações transnacionais, principalmente nos setores fármacos e de defensivos agrícolas defendem a preservação do patrimônio genético para suas exploraç̃̃es biotecnológicas. Os grupos e organizações ambientalistas atuam na perspectiva da proteção dos recursos naturais pelo seu valor intrínseco, embora em alguns casos deixem dúvidas quanto aos reais interesses externos nesses territórios biodiversos. Os bancos multilaterais, pressionados pela opinião pública internacional para a conservação da biodiversidade passam a utilizá-la como critério e requisito básico para o financiamento de projetos a serem desenvolvidos, como na Amazônia, por exemplo. Já o governo brasileiro, no plano discursivo, aceita e divulga a importância da biodiversidade para o desenvolvimento regional com bases sustentáveis da região. As comunidades extrativistas são convencidas de que a conservação dos ecossistemas é condição básica para sua própria sobrevivência. E as comunidades tradicionais se conscientizam que seus conhecimentos biogenéticos da região são fundamentais para o aproveitamento econômicos dos recursos existentes naquele território.

O desmatamento da floresta amazônica, ocorrido na metade da década de 1980 levou as questões relacionada a floresta para o centro do debate ecológico mundial, nascendo assim, o próprio conceito de biodiversidade. Nesse momento, o mundo atentava-se para a importância das florestas tropicais, as quais detinham em seu território os habitats mais ricos em espécies do planeta, entretanto, devido o alto grau de desmatamento, corriam o maior risco de extinção (SANTOS, 2005), sendo que muitas delas jamais serão conhecidas pela humanidade. Escobar e Pardo (2005) acrescentam que as florestas tropicais passam a ser cenários de novos impulsos de formas de desdobramentos do processo de monopolização capitalista.

No passado. a biodiversidade, entendida como diversidade de formas de vida - plantas, animais, microorganismos - era tida como base para a sobrevivência de comunidades pobre. Entretanto, desde o século passado a idéia de biodiversidade tem-se configurado, no contexto mundial, como a base ecológica para a vida e, sobretudo como o "capital natural" para dois terços da humanidade que investe na biodiversidade como forma de produção para desenvolver as atividades agrícolas, pesqueiras, de saúde e produção de utensílios. Dessa forma, as indústrias globais encontram na biodiversidade fontes de matéria-prima como alternativa para suprir as falhas apresentadas nas antigas tecnologias químicas (SHIVA, 2005).

Na agricultura, após o reconhecimento das falhas apresentadas no controle de pragas, via produtos químicos, a utilização de pesticidas de origem vegetal vem se difundindo cada vez mais, viabilizando investimentos neste ramo industrial. Já no setor de saúde, a indústria farmacêutica ocidental passa a utilizar o princípio de plantas, aderindo ao sistema da medicina indiana e chinesa (SHIVA, 2005).

Conforme Alonso (2005), a indústria farmacêutica e alimentar mundial dependem dos recursos naturais para continuar suas investigações e adquirir maior número de produtos. Como resultado dessa dependência, tem-se a constante pressão, principalmente para salvaguardar os investimentos no setor da biotecnologia.

Dessa forma, os conhecimentos das populações tradicionais, como exemplo indígenas, são explorados, princípios ativos, destinados a combate e cura de doenças, 
são descobertos, principalmente pelos países detentores de tecnologia, os quais têm lutado pelos direitos de propriedade intelectual associados ao comércio entre países, com soberania para as multinacionais.

Evidentemente, o conhecimento das populações tradicionais tem sido a chave para tal descoberta. Segundo Rafi (1994 apud ALONSO, 2005), através de observações, as empresas farmacêuticas constataram que a prospecção biológica é viabilizada quando três comunidades utilizam a mesma substância com fins medicinais.

Entretanto, os novos sistemas de patentes e os direitos de propriedade intelectual ameaçam apropriar-se dos recursos e processos de conhecimentos vitais dos países do Sul, resultando sem dúvidas em monopólio para as empresas do Norte, onde as patentes estão no centro do novo colonialismo (SHIVA, 2005). Jameson (1991 apud SANTOS, 2005, p. 127) complementa, destacando que "a colonização tem efeitos devastadores sobre a política, as lutas de resistência e os anseios de emancipação".

Nessa análise, devido ao aporte financeiro e político, os países do Norte, proporcionaram o surgimento de novas tecnologias, como a biotecnologia, aumentando ainda mais o controle sobre os mercados mundiais e dos recursos naturais, influenciando nas políticas globais face ao controle territorial dos países detentores de biodiversidade. Trata-se de um novo tipo de colonialismo, onde os países do Sul, detentores da maior biodiversidade do planeta, continuam a ser meros fornecedores de matérias-primas, como em tempos passados. Vale ressaltar que o conhecimento tradicional permanece à margem dessa relação e nem ao menos é reconhecido.

Nesse momento, os avanços da tecnociência, mais específico da biotecnologia, mostram a importância que os recursos genéticos iriam desempenhar na economia do futuro. Essas evidências foram discutidas antes da Eco-92, onde os países desenvolvidos advogavam a favor do livre acesso aos recursos genéticos, defendendo a idéia que a biodiversidade pertence a todos, portanto não é propriedade de ninguém (SANTOS, 2005).

A biopirataria é tida como o processo de patentear frações e produtos da biodiversidade, com base nos conhecimentos das populações indígenas. Porém, o patenteamento dos produtos além de negar as inovações e criatividades acumuladas das populações tradicionais transformam-se em instrumentos de enclausuramento dos bens intelectuais e biológicos capazes de tornar a sobrevivência possível. Contudo, se a biopirataria não for barrada, só restará aos povos dos países em desenvolvimento se submeterem à compra de suas próprias sementes e os seus medicamentos a preços elevados impostos pelas empresas globais que manipulam a indústria da biotecnologia e farmacêutica (SHIVA, 2005).

Assim, fica claro o domínio dos países do Norte em relação à biodiversidade dos territórios dos países do Sul. Configura-se dessa maneira, uma disputa acirrada, no âmbito da política internacional face ao controle pela biodiversidade, situação em que certamente os países detentores de capital e tecnologia sempre dispõem de privilégios no tocante a temática apresentada. Trata-se, portanto da versão moderna do colonialismo, o biocolonialismo.

Conforme Santos (2005), o Brasil defendeu a tese de que o acesso aos recursos naturais deveria ser regulamentado por acordo, a critério do país que dispõe territorialmente dessa biodiversidade, tendo como base o princípio do direito soberano do Estado sobre os recursos existentes em seu território. Sendo assim, para que os recursos genéticos passassem a ser patrimônio mundial, deveria haver uma 
transferência de biotecnologia visando favorecer a conservação desse patrimônio.

Nessa ótica, já que o direito à propriedade intelectual é fato consumado, nada mais justo que parte dos lucros resultante do favorecimento da propriedade intelectual fosse repassada para os países detentores de biodiversidade.

\section{UNIDADES DE CONSERVAÇÃO COMO ESTRATÉGIA DE GESTÃO TERRITORIAL DOS RECURSOS NATURAIS}

Diante da crise ambiental, anunciada como crise mundial, evidenciada principalmente a partir da década de 1970, os especialistas debruçaram-se sobre a criação de um instrumento internacional que tratasse da Conservação da Diversidade Biológica planetária.

As iniciativas se desenvolveram durante a década de 1980, sendo que em 1992, durante a Eco-92, 150 países adotaram a convenção global que entra em vigor em 1993. Dessa forma, a CDB se configura num marco político, portanto, devendo ser seguida pelos países signatários (BENSUSAN; BARROS; BULHÔES et al, 2006).

O Decreto Legislativo $n^{\circ} 2$, de 1994, aprova o texto sobre a Convenção sobre Diversidade Biológica (CDB), que tem como objetivo a utilização sustentável de seus componentes e a repartição justa e equitativa dos benefícios derivados da utilização dos recursos genéticos, mediante o acesso adequado aos recursos genéticos e a transferência adequada de tecnologias pertinentes, levando em conta todos os direitos sobre tais recursos e tecnologias, e financiamento adequado (BRASIL, 1994). No âmbito da convenção um sistema adequado de UCs é considerado o pilar central para o desenvolvimento de estratégias nacionais de preservação da diversidade biológica.
A CDB é o mais importante tratado internacional sobre diversidade biológica, do qual o Brasil é signatário, acatando, portanto seus princípios e determinações, devendo segui-los e implementá-los. Esse tratado foi assinado pelo Presidente da República durante a Conferência das Nações Unidas sobre Meio Ambiente e Desenvolvimento (CNUMAD) em 1992; ratificada pelo Congresso Nacional, pelo Decreto Legislativo $\mathrm{n}^{\mathrm{o}} 2 / 94$, em 1994; e promulgada através do Decreto $\mathrm{n}^{\circ} 2.519$, em 1998 (BRASIL, 2006). Nesse tratado, os países signatários se comprometem a recuperar e restaurar ecossistemas degradados, promover a recuperação de espécies ameaçadas mediante, entre outros meios, a elaboração e implementação de planos e estratégias de gestão.

Para Inoue (2009), existe uma separação entre dois conjuntos de literaturas, uma focada nos aspectos internacionais-globais e outra nos aspectos locais-regionais. Dessa forma, dificulta-se a visão integrada sobre a questão da biodiversidade.

A autora acrescenta ainda que nas tentativas de análise, as dimensões global e local acabam se separando. Entretanto, as duas são interligadas, uma vez que para atingir a proteção global da biodiversidade há uma dependência de ações locais. Allbagli (1998 apud INOUE, 2009) destaca que os maiores desafios rumo à implementação da CDB encontram-se exatamente na esfera local, onde comumente as estratégias rumo a proteção ainda são insuficientes diante do grau de ameaça existente nesses espaços legalmente protegidos.

Yearkey (1996 apud GUILHERME, 2007) apresenta outras duas formas de interferência dos atores globais, além dos tratados e convenções em regimes globais, as Organizações Não Governamentais (ONGs) que advogam sobre a globalização dos problemas ambientais e as Empresas e Autoridades Locais. Em sua análise as ONGs globais, como Amigos da Terra, 
Greenpeace e WWF, são responsáveis pela maioria das campanhas globais e conscientização, arregimentação de grupos de atuação e poder de barganha e veto para dotação internacional em programas próprios ou de interesse ambiental, gradualmente foram se incorporando na participação e representação em organismos internacionais de formulação de políticas globais que interferem localmente.

Para Dobson (1990 apud GUILHERME, 2007), é simplesmente falsa a idéia de que seja interesse geral a luta por uma sociedade sustentável e igualitária, pois uma parcela decisivamente influente da sociedade tem interesse material de prolongar a crise ambiental, sobretudo, por que há dinheiro envolvido na administração. Portanto, a idéia de considerar essas pessoas como parte do engendramento de uma mudança social profunda é utópica.

As UCs fazem parte do regime global de biodiversidade, entendido como o conjunto de elementos balizadores normativos e cognitivos, ao redor dos quais interagem os atores, produzindo, do global ao local, decisões, ações e dinâmicas de troca de recursos e de conhecimento sintonizados com a CDB.

No mundo contemporâneo, as UCs vêm se constituindo numa das principais formas de intervenção governamental, visando reduzir as perdas da biodiversidade face à degradação ambiental imposta pela sociedade (desterritorialização das espécies da flora e fauna). No entanto, esse processo vem sendo acompanhado por conflitos e impactos decorrentes da desterritorialização de grupos sociais (tradicionais ou não) em várias partes do mundo (VALLEJO, 2009).

Evidentemente, não se pode deixar de destacar os interesses dos países do Norte na obtenção dos recursos naturais para a fabricação de produtos, como medicamentos e cosméticos. Vale ressaltar a preocupação dos países do Sul em estabelecer mecanismos que lhes assegurem a justa remuneração pelo acesso aos recursos genéticos e aos conhecimentos tradicionais, a repartição equitativa aos benefícios oriundos do uso desses recursos (BENSUSAN; BARROS; BULHÕES et al, 2006).

Ainda na idéia dos autores, a CDB apresenta baixo nível de implementação, devendo assim, encontrar formas mais eficientes rumo à proteção dos recursos naturais. Entre as causas que obscurecem o futuro, estão o desequilíbrio do grau de implementação dos três principais objetivos da CDB, a saber: a conservação, o uso sustentável da biodiversidade e a repartição dos benefícios oriundos do uso dos recursos genéticos por determinados países. Dessa forma, pode-se dizer que as inovações apresentadas na CDB se diluíram devido a falta de implementação contínua.

O Brasil está entre os 17 países megadiversos, sendo o primeiro neste ranking, o qual reúne $70 \%$ das espécies animais e vegetais catalogadas no mundo, destacando-se ainda por agrupar entre 15 e $20 \%$ da biodiversidade mundial e o maior número de espécies endêmicas do planeta (DRUMMOND; ANTONINI, 2006).

Esses dados justificam os olhares e interesses constantes dos países do Norte para com os territórios biodiversos do Brasil, assim como para com outros países considerados megadiversos. Sendo assim, fica evidente, que jamais países iriam se reunir, em conferências mundiais em busca de alternativas para a proteção dos recursos naturais, se não por interesses nas potencialidades que esses recursos oferecem, principalmente para atender as necessidades da indústria biotecnológica, que acima de tudo gera recursos financeiros para esses países.

A criação de UCs, na perspectiva de proteção dos recursos naturais, é utilizada, pelos países detentores de tecnologia e capital, como estratégia de controle de 
espaços territoriais dotados de potencial de biodiversidade. No cerne dessa questão, esses países continuarão no controle do mercado mundial de produtos agrícolas e farmacêuticos além dos recursos naturais que estão sendo resguardados, geralmente em áreas protegidas, na desculpa que atenderão as necessidades das futuras gerações em suprir suas próprias necessidades.

Para ilustrar tal importância Crucible Group II (2001, apud ALONSO, 2005), destaca que na década de 1990, o setor de produtos bioindustriais diretamente ligados à agricultura, à produção de alimentos e à saúde se consolidaram na economia global concentrando gigantescas corporações transnacionais, onde as dez maiores empresas de agroquímicos controlaram 91\% do mercado global deste setor; as dez maiores companhias de sementes obtiveram um controle entre $25 \%$ e $33 \%$ do mercado mundial; e as empresas farmacêuticas responderam por $36 \%$ do total desse mercado.

Na análise de Escobar e Pardo (2005), os recursos naturais são usados numa perspectiva globalocêntrica, onde a biodiversidade é produzida pelas instituições dominantes, como o Banco Mundial e as organizações não governamentais ambientalistas dos países do Norte apoiadas pelos países do G-8. Essas empresas, objetivando manter o controle dos recursos naturais, oferecem subsídios para conservação e uso sustentável desses recursos nas mais variadas escalas, internacional, nacional e local. Em contra partida, sugerem mecanismos para a utilização desses recursos, principalmente com relação à investigação científica, a conservação in situ e ex situ, ao planejamento nacional da biodiversidade e ao estabelecimento de mecanismos de apropriação para a compensação e utilização econômica, sobretudo em troca dos direitos de propriedade intelectual. Fica evidente o poder da CDB em função da divulgação dessa perspectiva globalocêntrica em prol dos países do Norte.

Diante do exposto, algumas análises são dignas de nota. A primeira está atrelada ao poder desses países em dominar os territórios dos países detentores de biodiversidade, a exemplo do Brasil, onde grande parte dos biomas foi devastada e o que restou vem sendo transformada em UC, de forma que os recursos naturais fiquem resguardados, obviamente como reserva para apropriação do capital externo para atender a demanda da indústria farmacêutica estimada em bilhões de dólares anuais.

Na segunda análise, os espaços territoriais são reservados para o aumento da área destinada à produção agrícola. Obviamente, após a criação da Lei de Gestão de Florestas Públicas para Produção Sustentável, a qual prevê a liberação de concessões das florestas públicas para pessoas jurídicas (Lei $\left.n^{0} 11.284 / 2006\right)$ e da especulação em torno do debate sobre a modificação do Código Florestal para reduzir a área de Reserva Legal da Amazônia para 30\%, confirma-se a idéia de que esses espaços territoriais estavam sendo poupados para atender às necessidades descritas anteriormente, sobretudo, do agronegócio. Neste contexto, os territórios das UCs são usados estrategicamente como estoque para novos avanços do agronegócio. Assim, o slogan do desenvolvimento sustentável é utilizado pela mídia, sobretudo para mascarar as reais evidências.

\section{AS PRIMEIRAS ESTRATRÉGIAS DE PROTEÇÃO DOS RECURSOS NATURAIS}

A idéia de proteger recortes territoriais 
remonta à própria história da humanidade. Há evidências de que há milhares de anos os povos já reconheciam valores especiais. Dessa forma, esses povos tomavam medidas para proteger determinados sítios geográficos, principalmente, quando se tratava de animais sagrados, água pura, plantas medicinais e matéria-prima (MILLER, 1997 apud MORAES, 2004). Nesse contexto, os registros mais antigos documentam que os povos da Índia tinham a preocupação de proteger os peixes e outros animais, assim como as áreas de florestas (MORAES, 2004).

No Brasil, apesar da primeira área de proteção ter sido institucionalizada em 1937, com a criação do Parque Nacional Itatiaia, no Rio de Janeiro (CÉSAR; PAULA; GRANDO JUNIOR et al, 2003), há registros históricos indicando que a coroa portuguesa e o governo Imperial realizaram iniciativas de proteção, de gestão e controle dos recursos naturais, com o objetivo de garantir o controle sobre o manejo, principalmente, da madeira e da água. Durante o Império, D. Pedro II, o imperador ordenou que as fazendas devastadas para o plantio do café fossem desapropriadas e replantadas.

O desmatamento ao longo do período colonialismo comprometeu os estoques hídricos que serviam para abastecer parte do Rio de Janeiro. Assim, há indícios que as primeiras áreas protegidas tenham sido criadas em 1861, as Florestas da Tijuca e das Paineiras com a finalidade de resguardar os recursos hídricos daquela região (DRUMMOND, 1997; BARRETO FILHO, 2004 apud MEDEIROS, 2006). Em 1961, através de Decreto passou a ser chamada de Parque Nacional de Rio de Janeiro e em 1967, em virtude de confusões acerca da nomenclatura foi novamente alterada, passando a chamar-se Parque Nacional da Tijuca (IBAMA, 2004).

Entretanto, o modelo de UCs adotado no Brasil e nos países subdesenvolvidos, é considerado pelas literaturas como um dos principais instrumentos de estratégia para a proteção da natureza. Esse modelo originou-se nos Estados Unidos, tendo como marco a criação do Parque Nacional de Yellowstone em 1872, e expandiu-se para o Canadá e países da Europa, consolidando-se como um padrão mundial, principalmente após a década de 1960, quando o número e a extensão de espaços protegidos ampliaram-se pelo mundo. A concepção do modelo deriva da concentração de áreas protegidas com o objetivo de proteger a vida selvagem ameaçada pelo avanço da civilização urbano-industrial (CÉSAR; PAULA; GRANDO JUNIOR et al, 2003).

Para Brito (2000 apud Moraes, 2004), as bases para a criação do Parque Nacional de Yellowstone foram os fatores cênicos e históricos, além do potencial de lazer para a população urbana, porém num enfoque que iria tornar-se símbolo para o manejo de UCs criadas posteriormente em várias partes do mundo.

Na análise de Vallejo (2009), o conceito de parque nacional como área natural, selvagem, foi empregado nos Estados Unidos após o extermínio quase total de comunidades indígenas e a expansão para o oeste. Além da proposta de reservar grandes áreas naturais para fins de recreação para a população urbana que vinha crescendo rapidamente, havia uma preocupação de tornar o Yellowstone uma região reservada e proibida de ser colonizada, ocupada ou vendida segundo as leis americanas. Entretanto, não se considerou que os índios americanos tinham vivido em harmonia com a natureza por milhares de anos. Para os preservacionistas americanos, todos os grupos sociais eram iguais e a natureza deveria ser mantida intocada das ações negativas da humanidade.

Dessa forma, o modelo americano 
acabou se espalhando pelo mundo numa perspectiva dicotômica entre "povos" e "parques". Partindo-se do princípio de que a presença humana é sempre devastadora para a natureza, pois deixaram de considerar os diferentes estilos de vida das chamadas "populações tradicionais" existentes em outros países como na América do Sul e África.

Para Diegues (1993) essa postura preservacionista adotada nesse modelo de parques nacionais acabou resultando em conflitos que envolveram as populações extrativistas, pescadores e índios nos países subdesenvolvidos, onde a realidade era completamente diferente da existente nos Estados Unidos.

O problema gerado pela reprodução do modelo americano na criação de UCs no Brasil manifesta-se em conflitos junto às populações tradicionais que viviam no interior desses espaços territoriais que passaram a ser legalmente protegidos numa visão preservacionista. Essas comunidades possuíam culturas e práticas que caracterizam dependência da natureza, que, sobretudo guardam profundo conhecimento, a começar pelo seu território, mantido por várias gerações (DIEGUES, 1994 apud MORAES, 2004).

Vallejo (2009) complementa, ressaltando que essa forma de intervenção estatal na criação territórios protegidos, também foi responsável pelo processo de desterritorialização de vários grupamentos sociais, tradicionais ou não, que lá viviam antes da criação das unidades de conservação.

Evidentemente, com o processo de desterritorialização desses povos, consequentemente, essas populações tendem a ser reterritorializadas em outras localidades, notadamente, longe de suas raízes históricas/culturais, causando grandes perdas para as UCs, principalmente, quanto à propriedade intelectual, visto que essas populações conhecem de fato os recursos existentes nesses territórios, assim como foram responsáveis pela proteção desses espaços durante muito tempo.

Dessa forma, na análise de Haesbaert (2003), a desterritorialização aparece como o inverso de territorialização, e se concretiza no processo de desapropriação do espaço social, trazendo como consequência a multiplicação dos aglomerados de exclusão, trata-se, portanto, de espaços sobre os quais os grupos sociais dispõe de menor controle e segurança, material e simbólica.

Sendo assim, o território como disputa entre grupos antagônicos tem levado à desterritorialização dos mais fracos, neste caso representados pelas populações tradicionais e não-tradicionais que viviam nas UCs, sobretudo nas categorias de Proteção Integral, antes da sua criação.

\section{UNIDADES DE CONSERVAÇÃO NO BRASIL}

A Lei 9985/2000, do SNUC, estabelece critérios e normas para a criação, implantação e gestão das UCs. Porém, pode-se dizer que UCs não estão integradas de políticas de desenvolvimento e uso da terra em nível regional, representando em sua criação uma drástica intervenção do poder público sobre a sociedade regional e/ou local, que geralmente desconsidera os demais interesses em jogo. Mesmo que as unidades sejam efetivamente implantadas, sua simples criação, com a conseqüente redefinição do acesso aos recursos naturais da área, gera insegurança e instabilidade, fazendo com que, em alguns casos, o território de muitas delas seja dilapidado antes que sejam implantadas de fato, ou mesmo que as comunidades residentes no local permaneçam em situação de indefinição por longos anos, impossibilitadas de reorganizar satisfatoriamente suas vidas 
(CÉSAR; PAULA; GRANDO JUNIOR et al, 2003).

Entretanto, apesar de todo o aparato legal sobre os recursos naturais, um dos grandes desafios para a administração das UCs está relacionado ao tipo de desenho de uma UC que inclui além de seu tamanho e forma, a existência de zonas de amortecimento e de conexões entre elas e outras áreas naturais. Nesse sentido, um desenho inadequado pode gerar problemas derivados da fragmentação de habitats e da insularização. A ligação entre os ecossistemas naturais possibilitam entre elas o fluxo de genes e o movimento da biota, facilitando tanto a dispersão de espécies como a recolonização das áreas degradadas, além de promover a manutenção de populações que necessitam de áreas mais extensas para a sua sobrevivência (BENSUSAN, 2006).

Não obstante, existem outros obstáculos que vêm dificultando a gestão desses espaços territoriais, podendo-se citar entre eles: o problema da desapropriação de propriedades particulares; a permanência das populações consideradas tradicionais e não-tradicionais nas UCs de Proteção Integral; a aplicação das restrições de uso dos recursos naturais para as comunidades locais, no caso das unidades de uso direto; a superposição das UCs com reservas indígenas, áreas militares; a extração inadequada dos recursos naturais; e a falta de conectividade entre as unidades.

A gestão de UCs implica na análise da forma de apropriação desses territórios. Assim, entre os entraves mais difíceis de serem solucionados na administração dessas unidades encontra-se a questão fundiária, pois a maioria das pessoas, que se dizem "donos das terras", não têm documentos que comprovem a posse legal das mesmas. Esse impasse impede que os órgãos gestores possam conceder as devidas indenizações. Outro quesito é que essas terras, geralmente estão sob domínio de grandes latifundiários, comumente envolvidos nos processos de tomada de decisões. Já os proprietários que possuem títulos legais dificultam tais negociações em função da especulação imobiliária, exigindo altas indenizações que comumente ultrapassam aos valores do mercado imobiliário.

Na análise de Medeiros (2006), apesar no inegável avanço que proporcionou à questão de áreas protegidas do país, o SNUC, não conseguiu atingir plenamente sua pretensão inicial de criação de um sistema que pudesse integrar, por meio de um único instrumento, a criação e gestão das diferentes tipologias existentes no país. É notória no país a evidência de dificuldades existentes em função das disputas cada vez mais acirradas entre grupos que atuam ou têm interesse nas áreas de proteção no país.

Para Kolecom (2004 apud COHEN, 2007), a edição da lei do SNUC foi um grande avanço, no sentido de ter uniformizado a questão, no entanto, não basta mera existência da lei para que os problemas existentes sejam resolvidos. Seria necessário também garantir a efetiva participação da sociedade, de modo a implementar e até melhorar a própria legislação. Diegues (1993) acrescenta que é preciso também melhorara as condições de vida das populações tradicionais, sem afetar a relação mais harmoniosa com a natureza. A conservação custa caro, não somente em fiscalização, criação de infra-estrutura, etc., mas em investimentos sócio-econômicos e culturais que beneficiem populações tradicionais.

A gestão e o gerenciamento das UCs federais encontram-se sob administração do Instituto Chico Mendes de Conservação da Biodiversidade, ICMBio, as UCs estaduais sob responsabilidade das Secretarias Estaduais do Meio Ambiente, as municipais pelas Secretarias Municipais, e as RPPNs pelos proprietários.

Em 2004, apenas 10,54\% da área terri- 
torial do Brasil era coberta por UCs, o que representava 101.4974.971 hectares. Deste total, 6,34\% estavam distribuídas nas categorias de uso indireto, Proteção Integral, e 3,53\% nas de Uso Sustentável (ISO, 2004 apud BENSUSAM, 2006).

Em 2005 o país contava com 914 UCs, distribuídas nas categorias do SNUC, o equivalente a 111.612.388 hectares, administradas pela espera federal e estadual considerado um número modesto tamanho ao potencial da biodiversidade existente. A criação de UCs de Proteção e Integral e de Uso Sustentável encontramse equilibradas, sendo 478 unidades territoriais de Proteção Integral e 436 de Uso Sustentável.

Porém, quando se analisam as esferas federal e estadual, com relação à área, percebe-se que o governo estadual investiu mais em UCs de Uso Sustentável com 44.397.707 hectares, destacando-se a criação de APAs em todo o país, consideradas mais próximas de um mecanismo para ordenamento de uso da terra (RYLANDS; BRANDON, 2005). A criação de UCs de Uso Sustentável tem gerado menos conflitos com as populações tradicionais ou não-tradicionais, uma vez que é permitida a utilização direta de parte dos recursos naturais existes. Já o governo federal investe mais em UCs de Proteção Integral, apesar de 111 contra 367 estaduais, a área das unidades federais é muito maior, com 28.245.729.

Com relação às RPPNs, conforme dados do IBAMA (BRASIL, 2009), em 2009 o país contava com 500 unidades, distribuídas em 471.907,17 ha, sob administração de seus proprietários particulares. Entre os Estados destacam-se com maior número de RPPNs em seu território, Minas Gerais com 82, e com menor número Sergipe e Roraima, ambos com três unidades dessa categoria. Na Região Nordeste o Estado da Bahia se destacava com 75 unidades dessa natureza.

A Amazônia Legal (Mato Grosso, Ama- zonas, Acre, Amapá, Roraima, Rondônia, Tocantins e parte do Maranhão) possuía até 2009, 286 UCs, cerca de $20 \%$ do seu território, sob a administração federal, estadual e municipal (INSTITUTO SOCIOAMBIENTAL, 2009), totalizando 299, incluindo as 13 RPPNs.

Do total de UCs existentes em 2007 na Amazônia Legal, 183 eram de Uso Sustentável e 104 de Proteção Integral. Conforme Borges, Iwagana, Moreira e Dugigan (2007), os governos estaduais usam como estratégia a criação de UCs de Uso Sustentável, uma vez que gera menos conflitos entre o poder público e as populações locais. A criação de áreas de Proteção Integral implica na remoção de populações locais e gastos do poder público em indenizações para as desapropriações, aumentado, dessa forma, os conflitos nesses recortes espaciais.

Quanto aos conflitos existentes na administração esses territórios na Amazônia Legal, pode-se destacar: a) a sobreposição de áreas entre as UCs e outras áreas da união como as terras militares, as reservas garimpeiras, as áreas indígenas e os assentamentos agrícolas; b) a falta de infraestrutura, mesmo para unidades criadas há muito tempo; c) a falta de recursos humanos capacitados; e, d) a falta de recursos financeiros (BORGES; IWANAGA; MOREIRA et al, 2007).

Para que as UCs cumpram os objetivos para os quais foram criadas, é necessário pensar não somente na gestão interna desses espaços, mas sim em buscar alternativas para minimizar os problemas externos que afetam diretamente as unidades, uma vez que as pressões que ocorrem no entorno dessas áreas se apresentam de fora para dentro, sendo assim, a visão do gestor das unidades deve envolver os territórios circunvizinhos que de alguma forma possam comprometer a proteção desses ecossistemas.

Contudo, não basta apenas multiplicar 
a quantidade de unidades no país, a exemplo do Estado de Sergipe que possuía até 2009, quinze UCs, sendo seis de Proteção Integral e nove de Uso Sustentável. O que mais tem despertado a atenção neste cenário, é que no intervalo de 2004-2009 foram criadas seis unidades, e mais três estão em processo de criação. No entanto, esses espaços territoriais apresentam os mais variados problemas que vem dificultando a gestão e o gerenciamento desses "espaços legalmente protegidos", tais como: a falta de política florestal estadual; a inexistência de plano de manejo em todas as unidades; a falta de regularização fundiária; a falta de infra-estrutura administrativa e operacional; a falta de profissionais qualificados via concurso público; os mais variados impactos ambientais provocados pelas populações de áreas circunvizinhas e por grandes empreendedores; as ocupações desordenadas em áreas de risco ambiental; a especulação imobiliária; e a falta de realização de programas de educação ambiental.

Nesta análise, ficam alguns questionamentos, como por exemplo, para que criar tantas unidades, num curto intervalo de tempo, se as que foram criadas encontramse permeadas de problemas que dificilmente serão resolvidos? A quem pertencem as terras onde as UCs foram e estão sendo criadas? Quais os interesses que estão em jogo, uma vez que há unidades que foram criadas há quase 20 anos, e, no entanto não dispõe ao menos de plano de manejo? O que deve ser protegido, o que pode ser utilizado e para quem usufruir? Será que não é para reservar as terras para atenderem as necessidades do agronegócio num futuro bem próximo? Essas e outras questões também estão inseridas na história da maioria das UCs do país.

As relações de poder estabelecidas nesses territórios são explícitas, pois o Estado passa a controlar os recursos naturais, no caso das UCs de Proteção Integral, proi- bindo o acesso aos recursos naturais disponíveis para as populações tradicionais e de entorno, e nas de Uso Sustentável limitando o uso territorial. Nesse sentido, a política de conservação é feita sob égide do Estado ou de um agenciamento para interesses do grande capital.

Apesar do avanço significativo das políticas referentes aos espaços protegidos do país, é notório que apenas a existência dos instrumentos, do sistema e das instituições responsáveis não garante sua efetividade e eficiência. Para a gestão territorial dessas áreas, faz-se necessário a introdução de mecanismos mais sólidos e perenes de planejamento e financiamento. A falta de planejamento a curto, médio e longo prazo e o aporte de recursos, financeiros e humanos, estão entre os principais entraves na consolidação efetivas das áreas protegidas no país, mas a questão fundiária, sem dúvidas, encontra-se no âmago dessa questão, principalmente por envolver relações de poder no uso do território.

Dessa forma, torna-se necessário estabelecer com mais precisão a integração das áreas protegidas com as várias escalas de planejamento e gestão do território, atualmente reconhecidas através de mosaicos e dos corredores ecológicos. Apesar da existência do SNUC, na prática as experiências e os resultados são pouco satisfatórios. Pode-se dizer que o SNUC não conseguiu contemplar definitivamente uma solução para os problemas de baixa integração e gerenciamento das áreas protegidas (MEDEIROS, 2006).

Há necessidade do fortalecimento da política de conservação, que englobe todas as áreas protegidas, como: as terras indígenas, reservas legais e as áreas de preservação permanente; além da importância de estabelecer a conectividade entre os espaços protegidos; e através da criação de corredores ecológicos e de novas UCs. Para Bensusan (2006), existem outros requisitos fundamentais neste processo, tais como: 
planejamento global do sistema; definição de critérios para seleção de novas UCs; resgate da importância das categorias do SNUC; fortalecimento da pesquisa científica nesses espaços; democratização nos processos de consulta pública previstas noSNUC; fortalecimento de programas de conservação em áreas particulares; apoio e respeito às comunidades tradicionais; construção coletiva na solução dos conflitos locais; capacitação continuada dos gestores e dos membros das UCs; geração de benefícios nesses espaços para a comunidade local; e a busca de parcerias com a comunidade local na perspectiva de uma gestão participativa.

\section{CONSIDERAÇÕES FINAIS}

Diante do processo de ocupação desenfreado e do uso predatório dos recursos naturais, porções do território dotadas de biodiversidade são reservadas na perspectiva de uma gestão territorial adequada. Porém, não se pode deixar de ressaltar, os interesses dos países do Norte nesses territórios, Assim, há evidências de que esses territórios vêm sendo reservados como garantia aos anseios do agronegócio. Nesse contexto, políticas de conservação, na escala internacional e nacional, foram criadas, com o intuito de resguardar esses recortes espaciais, criando-se as Unidades de Conservação, como principal mecanismo de conservação da natureza.

Há evidências de que os países desenvolvidos vêm controlando os territórios dotados de recursos naturais, considerados como fonte de matéria-prima para a indústria da biotecnologia, como a biogenética, a indústria de alimentos e de produtos agrícolas. No âmago desta questão, a criação de UCs, com o objetivo de proteger parcelas dos recursos naturais para as futuras gerações é utilizada como mais uma faceta do mercado capitalista, configurando-se assim uma nova forma de controle territorial, o biocolonialismo.

Neste cenário, a disputa acirrada pelos territórios dotados de biodiversidade também têm gerado conflitos que envolvem diferentes atores. Dê um lado, os donos do grande capital internacional, com interesse na proteção desses espaços, sobretudo devido ao seu potencial para atender à demanda da indústria farmacêutica e de cosméticos. Por outro lado, os donos do capital interno, interessados em resguardar esses territórios como reserva de terras para expansão do agronegócio. Neste contexto, sempre haverá as comunidades que dispõem de menor poder de barganha nesta disputa, as populações tradicionais, que são retiradas das UCs de Proteção Integral. Portanto, ficam evidentes as relações de poder estabelecidas nessas áreas protegidas, em prol dos grupos dominantes.

A criação de UCs, principalmente do grupo de Proteção Integral, vem sendo acompanhada pelo processo de desterritorialização dos mais fracos, as populações tradicionais, que são obrigadas a deixar esses espaços que antes ajudavam a proteger. Porém, a administração vem sendo marcada pelo descaso constante por parte das autoridades responsáveis.

Já as UCs de Uso Sustentável também apresentam os mesmo problemas de gestão, tendo como desafio estabelecer quais os recursos naturais que podem ser utilizados, quem deve utiliza-los e quanta dessa utilização é sustentável. Enquanto não se encontram mecanismos eficientes para resolução de tais questões, os atores envolvidos, principalmente as populações tradicionais e locais, continuarão esperando por uma gestão eficiente que atenda aos seus anseios e o das gerações futuras.

Dessa forma, apesar das UCs serem consideradas como um instrumento estratégico de gestão territorial pode-se dizer 
que o país ainda tem um longo caminho a percorrer, visto que essas áreas continuam relegadas aos mesmos problemas históricos de administração e gerenciamento. Nessa ótica, faz-se necessário novos olhares rumo a minimização dos conflitos políticos, legais, econômicos, territoriais, sociais, culturais e ambientais que vem dificultando a gestão desses espaços.

Para alcançar a minimização dos conflitos, na perspectiva de uma gestão participativa, é necessário o envolvimento dos atores que possuem interesses na conservação dessas áreas. Nessa perspectiva, é necessário repensar nos desenhos das UCs de forma que impeça a fragmentação e o isolamento da área, de modo a que a sociedade civil possa participar de forma ativa na busca de alternativas para minimização, tanto dos problemas internos como externos desses espaços, uma vez que também exercem fortes pressões sobre as unidades. Nessa análise, a participação efetiva dos moradores locais, é fundamental para apontar pressupostos objetivando o uso e ordenamento desses territórios.

Para implementação de fato das UCs in locu, vários desafios, rumo a uma gestão participativa e gerenciamento efetivo, devem ser enfrentados, tais como: fortalecimento da política de ordenamentos territorial dos recursos naturais englobando todas as áreas protegidas; elaboração de política florestal estadual; estratégia de áreas prioritárias visando o estabelecimento de conectividade entre as unidades, como por exemplo, criação de RPPNs, corredores ecológicos e zonas de amortecimento; elaboração do plano de manejo, plano de gestão e de zoneamento econômicoecológico das unidades; regularização fundiária; realização de concurso público; captação de recursos; melhoraria na infraestrutura administrativa e operacional; ampliação das pesquisas; disponibilização para solucionar conflitos locais e insti- tucionais; estabelecimento de parcerias entre os órgãos estatais e as organizações da sociedade civil; valorização do conhecimento tradicional; utilização dos recursos naturais pelas populações tradicionais e comunidades locais; e a realização de programas de educação ambiental.

Outra estratégia importante é a criação de comitês de gestão participativa com atuação de representantes dos diversos segmentos da sociedade, tais como: do ICMBio, das Secretarias Estaduais do Meio Ambiente, do Conselho de Meio Ambiente Estadual, dos Comitês de Bacias Hidrográficas, das Prefeituras Municipais, dos setores produtivos, das instituições técnico-científica e dos conselhos de comunidades com a finalidade buscar soluções tanto para os conflitos internos como para os externos, uma vez que exercem profundas pressões sobre os ecossistemas.

Somente por meio de iniciativas dessa natureza poder-se-á pensar em dar aos espaços territoriais legalmente protegidos a finalidade para os quais foram criados, sejam eles de Proteção Integral ou de Uso Sustentável.

\section{REFERÊNCIAS}

ALBAGLI, Sarita. Amazônia: fronteira geopolítica da biodiversidade. Pareceristas Estratégicas, n. 12, set. 2001. Disponível em: < http://jadsonporto. sites.uol.com.br/sarita.pdf $>$. Acesso em: 5 maio 2009.

ALONSO, Margarita Flórez. Proteção do conhecimento tradicional? In: SANTOS, Boaventura de Sousa (Org.). Semear outras soluções: os caminhos da biodiversidade e dos conhecimentos rivais. Rio de Janeiro: Civilização Brasileira, 2005.

BENSUSAN, Nurit; BARROS, Ana Cristina; BULHÕES, Beatriz; BARRETTO FILHO, Henyo Trindade. Introdução. In: BENSUSAN, Nurit; BARROS, Ana Cristina; BULHÕES, Beatriz; ARANTES, Alessandra (Orgs.). Biodiversidade: para comer, vestir ou passar no cabelo? Para mudar o mundo! 
São Paulo: Peirópolis, 2006.

BENSUSAN, Nurit. Conservação da biodiversidade em áreas protegidas. Rio de Janeiro: FGV, 2006.

BORGES, Sérgio Henrique; IWANAGA, Simone; MOREIRA, Marcelo; DURIGAN, Carlos César. Uma análise geopolítica do atual sistema de unidades de conservação na Amazônia Brasileira. In: CI BRASIL (Conservação Internacional): Política Ambiental - Conservação Internacional-Brasil. Belo Horizonte: CI Brasil, 2007.

BRASIL. Decreto Legislativo n. 2, de 3 de fevereiro de 1994. Aprova o texto da convenção sobre diversidade biológica. Brasília: MMA, 1994.

. IBAMA. Parque Nacional da Tijuca. Brasília: IBAMA, 2004. Disponível em: < http://www. ibama.gov.br/siucweb/mostraUc.php?seqUc=7 >. Acesso em: 22 jun. 2009.

. IBAMA. Atlas de conservação da natureza brasileira: unidades federais. São Paulo: METALIVROS, 2004.

IBAMA. Relatório resumido das RPPN por estado. Disponível em: < http://www.ibama. gov.br/rppn/index.php?id_menu=73 >. Acesso em: 10 fev. 2009.

. Lei n. 9.985, de 18 de julho de 2000. Institui o Sistema Nacional de Unidades de Conservação da Natureza - SNUC. Brasília, 2000.

. Plano Nacional de Áreas Protegidas. Brasília, 2006.

. Relatório resumido das RPPNs por estado. IBAMA. Disponível em: < http://www.ibama.gov. $\mathrm{br} /$ siucweb/rppn/relatorio_resumido.rtf $>$. Acesso em: 5 fev. 2009.

CÉSAR, A. L.; PAULA, D.; GRANDO JUNIOR, E. S.; BARRETO FILHO, H. T; FALEIRO, R. P.; GANEN, R. S. Proposta de um procedimento pra a criação de Unidades de Conservação. In: LITTLE, P. E. (Org.). Políticas ambientais no Brasil: análises, instrumentos e experiências. Brasília: IIEB, 2003.

COHEN, M. 2007. Avaliação do uso de estratégias colaborativas na gestão de Unidades de Conser- vação do tipo Parque na cidade do Rio de Janeiro. Tese (Doutorado). Disponível em < http://www. maxwell.lambda.ele.puc-rio.br $>$ Acesso em: 15 nov. 2007.

COPABIANCO, J. P. R. Biomas brasileiros. In: CAMARGO, A.; COPABIANCO, J. P. R.; OLIVEIRA, J. A. P. (Orgs.). Meio Ambiente: avanços e obstáculos Pós Rio/92. Rio de Janeiro: Fundação Getúlio Vargas, 2002.

DIEGUES, Antônio Carlos. O mito moderno da natureza intocada. São Paulo: Hucitec, 1993. (Série Documentos e Relatórios de Pesquisa, n. 1)

DIEGUES, Antonio Carlos; NOGARA, Paulo José. O nosso lugar virou parque: estudo sócio-ambiental do Saco de Mamanguá - Parati - Rio de Janeiro. 2. ed. São Paulo: NAPAUB/USP, 1999.

DRUMMOND, G. M.; ANTONINI, Y. A contribuição da Fundação Biodiversitas para implementação do artigo $7^{\circ}$ da Convenção sobre Diversidade Biológica. In: BENSUSAN, N.; BARROS, A. C.; BULHÕES, A.; ARANTES, A. (Orgs.). Biodiversidade: para comer, vestir ou passar no cabelo? Para mudar o mundo! São Paulo: Peirópolis, 2006.

ESCOBAR, Arturo; PARDO, Maurício. Movimentos sociais e biodiversidade no Pacífico colombiano. In: SANTOS, Boaventura de Sousa (Org.). Semear outras soluções: os caminhos da biodiversidade e dos conhecimentos rivais. Rio de Janeiro: Civilização Brasileira, 2005.

GUILHERME, M. L. Sustentabilidade sob a ótica global e local. São Paulo: FAPESP, 2007.

HAESBAERT, Rogério. Desterritorialização: entre as redes e os aglomerados de exclusão. In: CASTRO, I. E.; GOMES, P. C. C.; CORRÊA, R. L. (Orgs.). Geografia: conceitos e temas. 5. ed. Rio de Janeiro: Bertrand Brasil, 2003.

INOUE, Cristina Yumie Aoki. O conceito de regime global de biodiversidade e experiências locais de conservação e desenvolvimento sustentável. Disponível em < http://www.mamiraua.org.br/admin/imgeditor/File/publicacoescientificas/2007/ artigo_1pdf >. Acesso em: 5 fev. 2009.

ISA - INSTITUTO SOCIOAMBIENTAL. Unidades de conservação na Amazônia legal. Disponível em: < http://www.socioambiental.org/uc/quadro_gera l >. Acesso em: 16 fev. 2009.

MEDEIROS, Rodrigo. Evolução das tipologias e categorias de áreas protegidas no Brasil. Ambiente 
e Sociedade, Campinas, v. 9, n. 1, jan./jun. 2006.

MORAES, Marília Britto Rodrigues de. Área de proteção ambiental como agência de desenvolvimento sustentável: APA Cananéia Iguape Peruíbe/ SP. São Paulo: FAPESP, 2004.

RYLANDS, Anthony B.; BRANDON, Katrina. Unidades de conservação brasileira. Megadiversidade, v. 1, n. 1. jul. 2005. Disponível em: < http://www. unifap.br/ppgbio/doc/06_rylands_brandon.pdf >. Acesso em: 15 fev. 2009.

SANTOS, Laymert Garcia dos. Quando o conhecimento tecnocientífico se torna predação highttech: recursos genéticos e conhecimento tradicional no Brasil. In: SANTOS, Boaventura de Sousa (Org.). Semear outras soluções: os caminhos da biodiversidade e dos conhecimentos rivais. Rio de Janeiro: Civilização Brasileira, 2005.

SANTOS, Milton. Metamorfose do espaço habitado. São Paulo: Hucitec, 1988.

SANTOS, Milton; SILVEIRA, Maria Laura. O Brasil: território e sociedade no início do século XXI. 3. ed. Rio de Janeiro: Record, 2001.

SHIVA, Vandana. Biodiversidade, direitos de propriedade intelectual e globalização. In: SANTOS, Boaventura de Sousa (Org.). Semear outras soluções: os caminhos da biodiversidade e dos conhecimentos rivais. Rio de Janeiro: Civilização Brasileira, 2005.

VALLEJO, Luiz Renato. Unidades de conservação: uma discussão teórica à luz dos conceitos de território e de políticas públicas. Disponível em: < http://www.uff.br/geographia/rev_08/luiz8.pdf >. Acesso em: 20 de fev. 2009.

Recebido em 24/07/2009

Aceito em 20/12/2009 